\title{
Bioequivalence of levamlodipine besylate tablets in healthy Chinese subjects: a single-dose and two-period crossover randomized study
}

Xin Li ${ }^{\dagger}$, Chenjing Wang ${ }^{\dagger}$, Ting Li, Yanping Liu, Shuqin Liu, Ye Tao, Yaping Ma, Xiaomeng Gao and Yu Cao* (D)

\begin{abstract}
Background: Levamlodipine, a calcium channel blocker, has been show act as a cardiovascular drug. To compare the pharmacokinetic parameters between levamlodipine (test formulation) at a single dose of $5 \mathrm{mg}$ and amlodipine (reference formulation) at a single dose of $10 \mathrm{mg}$, the bioequivalence study was carried out.

Methods: A single-dose randomized, open-label, two-period crossover study was designed in healthy Chinese subjects. 48 subjects were divided into fasted and fed groups equally. The subjects randomly received the test or reference formulations at the rate of 1:1. Following a 21-day washout period, the alternative formulations were received. The blood samples were collected at 1, 2, 3, 4, 5, 6, 7, 8, 9, 10, 11, 12, 14, 24, 36, 48, 72, 96, 120, 144, $168 \mathrm{~h}$ later. Liquid chromatography-tandem mass spectrometry (LC-MS/MS) was applied to determine the plasma concentrations of levamlodipine. Adverse events were recorded.

Results: The $90 \%$ confidence intervals (Cls) of the ratio of geometric means (GMRs) of $C_{\text {max }}, A \cup C_{0-t}$ and $A \cup C_{0-\infty}$ under both fasted and fed conditions were within the prespecified bioequivalence limits between $80 \sim 125 \%$. Under fasted conditions, 24 subjects were enrolled and completed the study. The mean $C_{\max }$ was $(2.70 \pm 0.49) \mathrm{ng} /$ $\mathrm{mL}$, $\mathrm{AUC}_{0-\mathrm{t}}$ was $(141.32 \pm 36.24) \mathrm{ng} \times \mathrm{h} / \mathrm{mL}$ and $\mathrm{AUC}_{0-\infty}$ was $(157.14 \pm 45.65) \mathrm{ng} \times \mathrm{h} / \mathrm{mL}$ after a single dose of $5 \mathrm{mg}$ levamlodipine. The mean $C_{\max }$ was $(2.83 \pm 0.52) \mathrm{ng} / \mathrm{mL}$, $A \cup C_{0-\mathrm{t}}$ was $(153.62 \pm 33.96) \mathrm{ng} \times \mathrm{h} / \mathrm{mL}$ and $A \cup C_{0-\infty}$ was $(173.05 \pm 41.78) \mathrm{ng} \times \mathrm{h} / \mathrm{mL}$ after a single dose of $10 \mathrm{mg}$ amlodipine. Under fed conditions, 24 subjects were enrolled and completed the study. The mean $C_{\max }$ was $(2.73 \pm 0.55) \mathrm{ng} / \mathrm{mL}$, $A \cup C_{0-t}$ was $(166.93 \pm 49.96) \mathrm{ng} \times \mathrm{h} / \mathrm{mL}$ and $A_{U} C_{0-\infty}$ was $(190.99 \pm 70.89) \mathrm{ng} \times \mathrm{h} / \mathrm{mL}$ after a single dose of $5 \mathrm{mg}$ levamlodipine. The mean $\mathrm{C}_{\max }$ was $(2.87 \pm 0.81)$ $\mathrm{ng} / \mathrm{mL} A \cup C_{0-\mathrm{t}}$ was $(165.46 \pm 43.58) \mathrm{ng} \times \mathrm{h} / \mathrm{mL}$ and $\mathrm{AUC}_{0-\infty}$ was $(189.51 \pm 64.70) \mathrm{ng} \times \mathrm{h} / \mathrm{mL}$ after a single dose of 10 mg amlodipine. Serious adverse event was not observed.
\end{abstract}

Conclusion: The trial confirmed that levamlodipine at a single dose of $5 \mathrm{mg}$ and amlodipine at a single dose of 10 $\mathrm{mg}$ were bioequivalent under both fasted condition and fed condition.

Trial registration: Cinicaltrials, NCT04411875. Registered 3 June 2020 - Retrospectively registered

Keywords: Levamlodipine, Amlodipine, Bioequivalence, Pharmacokinetics

\footnotetext{
* Correspondence: caoyu1767@126.com

${ }^{\dagger}$ Xin Li and Chenjing Wang contributed equally to this work.

Phase I Clinical Research Center, The Affiliated Hospital of Qingdao

University, Qingdao 266003, China
}

(c) The Author(s). 2020 Open Access This article is licensed under a Creative Commons Attribution 4.0 International License, which permits use, sharing, adaptation, distribution and reproduction in any medium or format, as long as you give appropriate credit to the original author(s) and the source, provide a link to the Creative Commons licence, and indicate if changes were made. The images or other third party material in this article are included in the article's Creative Commons. licence, unless indicated otherwise in a credit line to the material. If material is not included in the article's Creative Commons licence and your intended use is not permitted by statutory regulation or exceeds the permitted use, you will need to obtain permission directly from the copyright holder. To view a copy of this licence, visit http://creativecommons.org/licenses/by/4.0/. The Creative Commons Public Domain Dedication waiver (http://creativecommons.org/publicdomain/zero/1.0/) applies to the data made available in this article, unless otherwise stated in a credit line to the data. 
Table 1 Study design for the bioequivalence evaluation of levamlodipine

\begin{tabular}{llll}
\hline Groups & Number of cases & The first period & The second period \\
\hline Fasted group & 12 & $\mathrm{~T}^{\mathrm{a}}$ & $\mathrm{R}^{\mathrm{b}}$ \\
& 12 & $\mathrm{R}$ & $\mathrm{T}$ \\
Fed group & 12 & $\mathrm{~T}$ & $\mathrm{R}$ \\
& 12 & $\mathrm{R}$ & $\mathrm{T}$
\end{tabular}

${ }^{\mathrm{a}} \mathrm{T}$ : test formulation, levamlodipine besylate, $5 \mathrm{mg} /$ tablet, 1 tablet;

${ }^{\mathrm{b}} \mathrm{R}$ : reference formulation, amlodipine besylate, $10 \mathrm{mg} /$ tablet, 1 tablet

\section{Background}

Hypertension is one of the most common risk factors of cardiovascular disease and stroke, which can lead to serious complications [1]. Amlodipine, a dihydropyridine calcium antagonist, has therapeutic effect on hypertension and angina pectoris. Amlodipine acted by inhibiting the influx of calcium through L-type calcium channels into vascular smooth muscle cells, preventing vasoconstriction while simultaneously improving blood flow. Usually, amlodipine is prescribed at a daily dose of 5 and $10 \mathrm{mg}$, may reach bioavailability of $60 \sim 90 \%$ [2]..Amlodipine is an racemic mixture, including ( $R$ )-amlodipine and $(\mathrm{S})$-amlodipine, but only the latter has therapeutic activity [3]. (S)-amlodipine, known as levamlodipine, similar to amlodipine in pharmacology, also play a role in vasodilation and decreasing blood pressure $[4,5]$.

Pharmacokinetics of levamlodipine besylate $2.5-\mathrm{mg}$ tablet in healthy male subjects was studied previously [6]. However, pharmacokinetic studies for other doses of levamlodipine have not been fully carried out yet. Furthermore, the bioequivalence between levamlodipine and amlodipine has never been verified. The bioequivalence study was designed to compare the pharmacokinetic parameters between levamlodipine at a single dose of $5 \mathrm{mg}$ and amlodipine at a single dose of $10 \mathrm{mg}$.

\section{Methods}

\section{Ethics}

The trial was performed abiding by the Declaration of Helsinki [7], Good clinical practice (GCP) [8] and the guidelines of China National Medical Products Administration (NMPA). Relevant documents, including protocol, informed consent and drug inspection report were all approved independently by the Medical Ethics Committee of the Affiliated Hospital of Qingdao University (No.: QYFYEC 2018-065-01). All protocol violations have been reported to the Medical Ethics Committee.

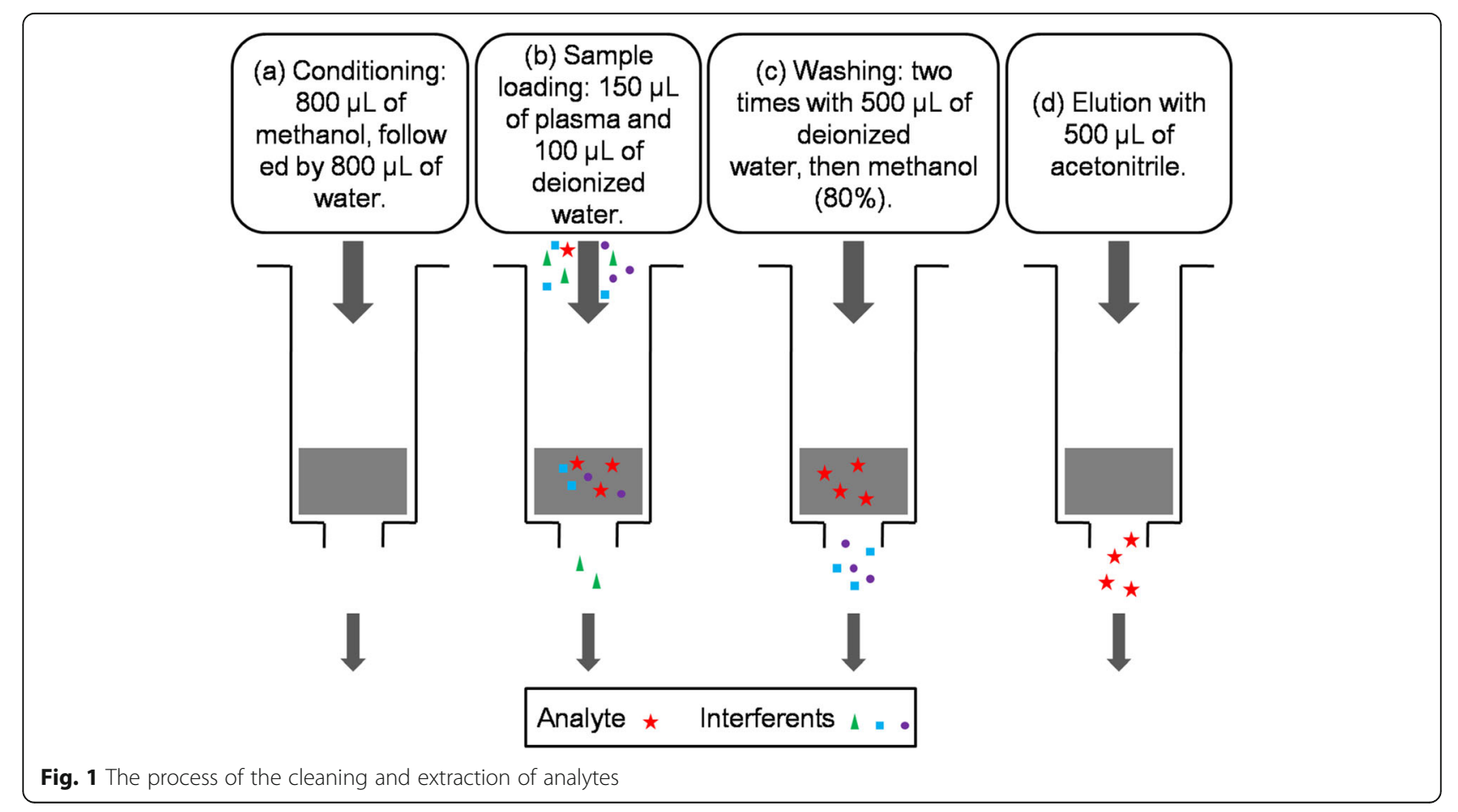




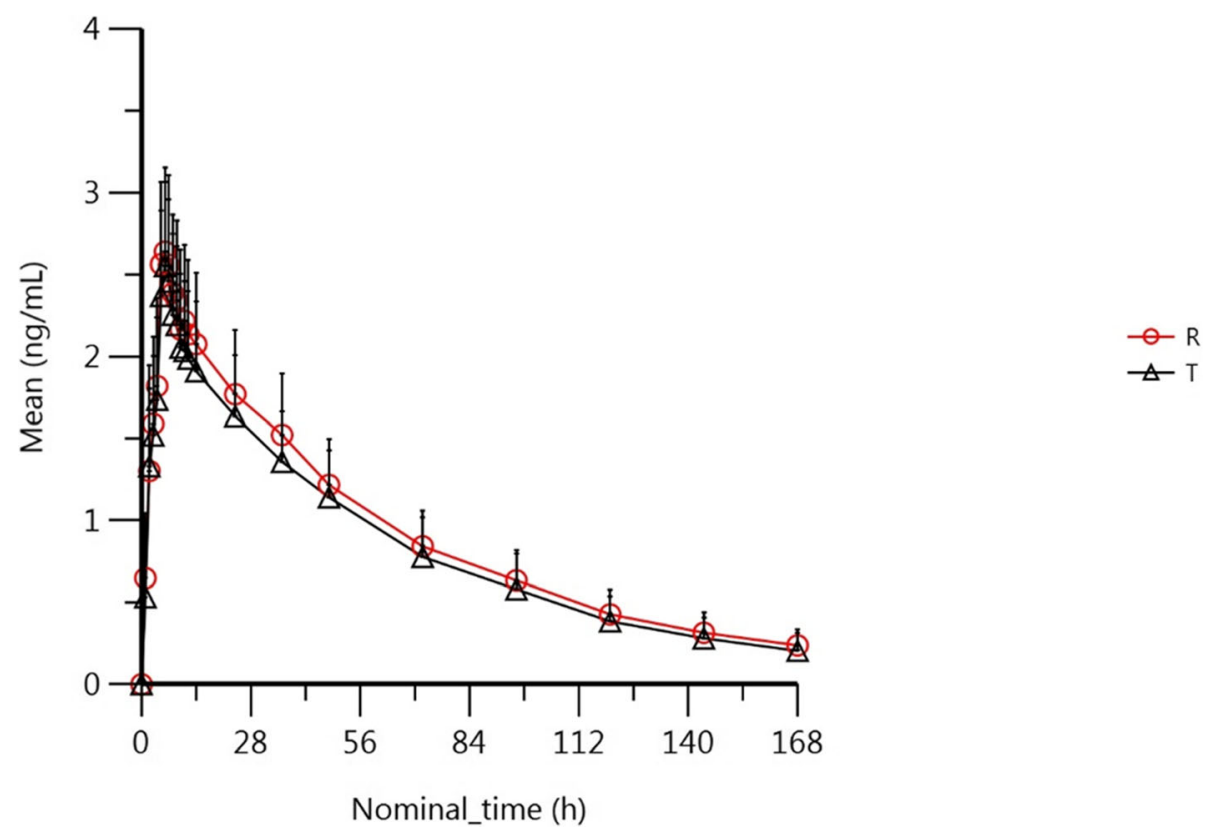

Fig. 2 The mean plasma concentration-time curves following a single dose of test formulations or reference formulations in the fasted group

\section{Subjects}

The inclusion criteria for the volunteers included as follows: 1) Healthy male and female aged 18 and above. 2) The body mass index is in the range of $18.6 \sim 28.5 \mathrm{~kg} / \mathrm{m}^{2}$ (including the boundary value). The weight of male is not less than $50.0 \mathrm{~kg}$, and that of female is not less than $45.0 \mathrm{~kg}$. 3) The following inspection indexs are normal and abnormal without clinical significance. The inspection including: vital signs, physical examination, blood routine, blood biochemistry, urinalysis, serological tests for hepatitis $B$ virus, hepatitis $C$ virus, human immunodeficiency virus (HIV), and syphilis virus, 12-lead electrocardiogram (ECG), breath test for alcohol, drug abuse test, pregnancy test for female. 4) The subjects have no

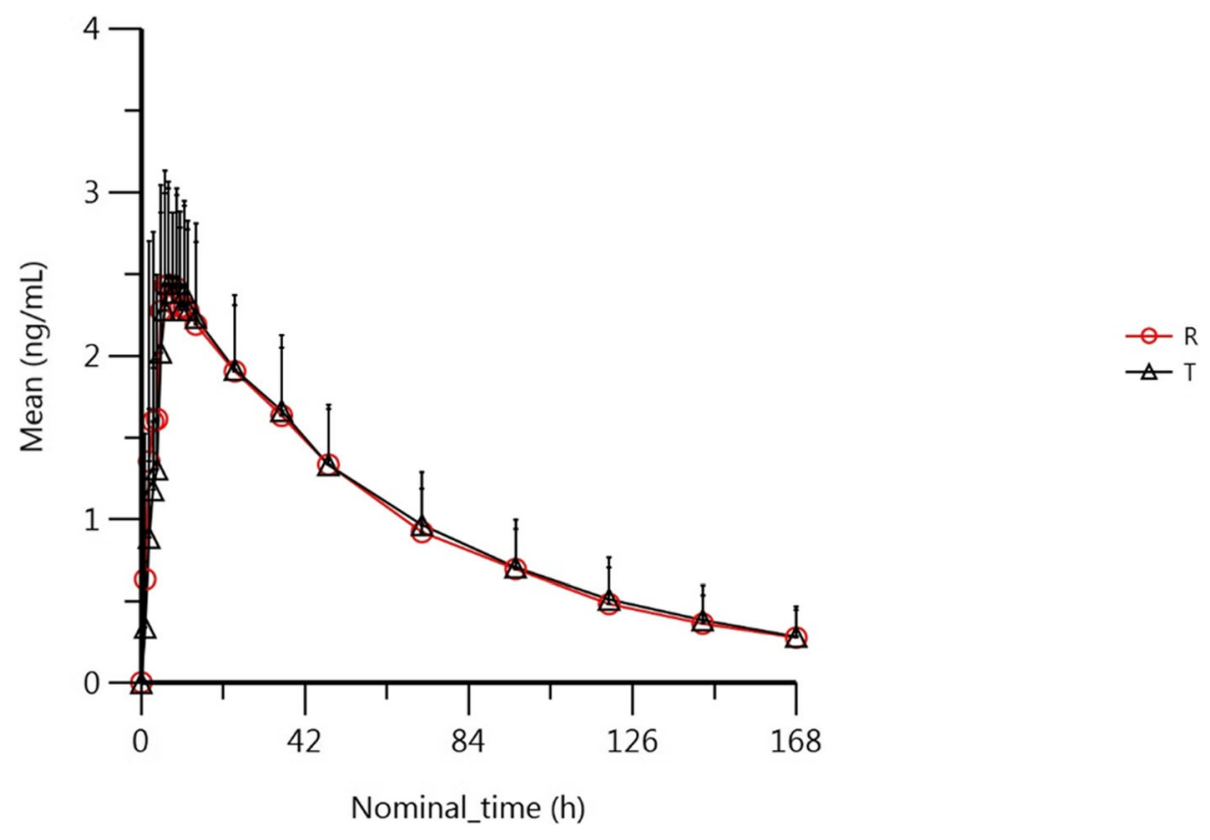

Fig. 3 The mean plasma concentration-time curves following a single dose of test formulations or reference formulations in the fed group 
family planning within 3 months and could select contraceptive method. 5) Before the study, all subjects have been informed of the study's purpose, protocal, benefits and risks, and signed the informed consent voluntarily.

The exclusion criteria included as follows: Being allergy to the study medications, smoking, alcohol abuse, and participation in another clinical trial within 3 months.

\section{Study design}

The single-dose randomized, open-label, two-period crossover study was executed in the Phase I Clinical Research Center of the Affiliated Hospital of Qingdao University. According to the random table generated by SAS 9.4, the subjects were divided into four groups (Table 1). The qualified volunteers were hospitalized in the Phase I Clinical Research Center, and fasted for $10 \mathrm{~h}$ overnight until administration. Levamlodipine at a single dose of 5 $\mathrm{mg}$ or amlodipine at a single dose of $10 \mathrm{mg}$ was swallowed with $240 \mathrm{ml}$ water at room temperature. $4 \mathrm{~mL}$ blood samples were taken before administration and at $1,2,3,4,5,6,7,8,9,10,11,12,14,24,36,48,72,96$, $120,144,168 \mathrm{~h}$ after administration. The samples were centrifuged at $1800 \mathrm{~g}$ for $10 \mathrm{~min}$ at $4{ }^{\circ} \mathrm{C}$ to separate the plasma. The plasma samples were divided into two aliquots and stored at $-80^{\circ} \mathrm{C}$ until bioanalysis. Since the half-life of levamlodipine is about $30 \sim 50 \mathrm{~h}$, washout period, the interval between two administration, was set at 21 days. The operation of the two periods was consistent. Moreover, in the fed group, the high-fat breakfast was arranged within half an hour before taking the medicine.

\section{Safety assessment}

The safety was assessed by monitoring vital signs and laboratory tests. Vital signs, such as body temperature, blood pressure, and heart rate, were measured before administration and at 3, 8, 24, 36, 48, 72, 96, 120, 144, 168 $\mathrm{h}$ after administration. Before removal from this study, the subjects were evaluated with blood routine, blood biochemistry, urinalysis, pregnancy test for female, and 12-lead ECG. For the adverse events (AEs), clinical symptoms, severity, occurrence and ending time, duration, treatment measures and the correlation with the drugs were recorded. All of the AEs that occur within the 7 half lives of the drug were recorded and followed up, unless the subjects returned to normal or stable, or failed to visit.

\section{Bioanalysis}

The analysts were blinded to the randomization. Plasma samples were determined by the liquid chromatographytandem mass spectrometry (LC-MS/MS), which was
Table 2 Pharmacokinetic parameters of levamlodipine test and reference formulations in the fasted group $(n=24)$

\begin{tabular}{lll}
\hline Parameter & \multicolumn{2}{l}{ Arithmetic mean \pm SD $(\% \mathbf{C V})^{\mathbf{a}}$} \\
\cline { 2 - 3 } & $\mathbf{T}$ & $\mathbf{R}$ \\
\hline $\mathrm{C}_{\max } / \mu \mathrm{g} \times \mathrm{L}^{-1}$ & $2.70 \pm 0.490(18.2 \%)$ & $2.83 \pm 0.516(18.2 \%)$ \\
$\mathrm{AUC}_{0-\mathrm{t}} / \mu \mathrm{g} \times \mathrm{h} \times \mathrm{L}^{-1}$ & $141.32 \pm 36.24(25.65 \%)$ & $153.62 \pm 33.96(22.10 \%)$ \\
$\mathrm{AUC}_{0-\infty} / \mu \mathrm{\mu g} \times \mathrm{h} \times \mathrm{L}^{-1}$ & $157.14 \pm 45.65(29.05 \%)$ & $173.05 \pm 41.78(24.15 \%)$ \\
$\mathrm{T}_{1 / 2} / \mathrm{h}$ & $49.46 \pm 11.35(22.95 \%)$ & $52.92 \pm 14.51(27.42 \%)$ \\
$\mathrm{t}_{\max }{ }^{*} / \mathrm{h}$ & $6.00(2.00,8.00)$ & $6.00(3.00,12.00)$ \\
\hline
\end{tabular}

${ }^{a}$ All values are represented as arithmetic mean \pm standard deviation $(\mathrm{CV}, \%)$ with [geometric mean] unless otherwise specified. *tmax is shown as median (minimum-maximum)

tested by Suzhou Shenglin Pharmaceutical Technology Co., Ltd. An ACQUITY ultra-high-performance liquid chromatography unit (SHIMADZU, Nexera UHPLC LC30A, Japan) and a mass spectrometer (Applied Biosystems, MDS Sciex, Triple Quad 6500 plus, Concord, Canada) were used in the study. Under multiple reaction monitoring, LC-MS/MS system adopts positive ionization mode. Data collection and analysis was employed with Analyst 1.6.3 software (Applied Biosystems, Foster City, CA, U.S.A.). The solid-phase extraction (SPE) experiments [9] were performed by HLB 96well Plate (Waters Oasis, WAT058951). The plate contains a reversed phase functionalized polymeric sorbent ( $30 \mathrm{mg} /$ well), in which particle size is $30 \mu \mathrm{m}$.

Figure 1 summarized the process of the cleaning and extraction. The cartridges were activated by $800 \mu \mathrm{L}$ of methanol and cleaned by $800 \mu \mathrm{L}$ of deionized water. The column was loaded with $150 \mu \mathrm{L}$ of plasma sample or calibrator, $50 \mu \mathrm{L}$ of working fluid $(5 \mathrm{ng} / \mathrm{mL})$ and $100 \mu \mathrm{L}$ of deionized water. Clean the column twice with $500 \mu \mathrm{L}$ deionized water. The column was depolarized with $80 \%$ methanol and washed twice with $500 \mu \mathrm{L}$ pure acetonitrile to elute levamlodipine. Dry the solution with the pure nitrogen stream. $150 \mu \mathrm{L}$ of pure acetonitrile was add into each sample, and mixed at room temperature for $10 \mathrm{~min}$. Finally, $20 \mu \mathrm{L}$ of the sample was injected into the LC-MS / MS system.

Table 3 Pharmacokinetic parameters of levamlodipine test and reference formulations in the fed group $(n=24)$

\begin{tabular}{lll}
\hline Parameter & \multicolumn{2}{l}{ Arithmetic mean \pm SD $(\% C V)^{\mathbf{a}}$} \\
\cline { 2 - 3 } & $\mathbf{T}$ & $\mathbf{R}$ \\
\hline $\mathrm{C}_{\max } / \mu \mathrm{gg} \times \mathrm{L}^{-1}$ & $2.73 \pm 0.547(20.1 \%)$ & $2.87 \pm 0.812(28.3 \%)$ \\
$\mathrm{AUC}_{0-\mathrm{t}} / \mathrm{\mu g} \times \mathrm{h} \times \mathrm{L}^{-1}$ & $166.93 \pm 49.96(29.93 \%)$ & $165.46 \pm 43.58(26.34 \%)$ \\
$\mathrm{AUC}_{0-\infty} / \mathrm{Mg} \times \mathrm{h} \times \mathrm{L}^{-1}$ & $190.99 \pm 70.89(37.12 \%)$ & $189.51 \pm 64.70(34.14 \%)$ \\
$\mathrm{T}_{1 / 2} / \mathrm{h}$ & $53.38 \pm 10.99(20.58 \%)$ & $53.56 \pm 13.41(25.05 \%)$ \\
$\mathrm{t}_{\max }{ }^{*} / \mathrm{h}$ & $7.00(5.00,14.00)$ & $7.00(2.00,24.00)$ \\
\hline
\end{tabular}

${ }^{a} \mathrm{All}$ values are represented as arithmetic mean \pm standard deviation $(\mathrm{CV}, \%)$ with [geometric mean] unless otherwise specified. *tmax is shown as median (minimum-maximum) 
Table 4 ANOVA results of main pharmacokinetic parameters in the fasted group

\begin{tabular}{|c|c|c|c|c|c|c|c|c|}
\hline \multirow{2}{*}{$\begin{array}{l}\text { Dependent } \\
\text { variable }\end{array}$} & \multicolumn{2}{|c|}{ Subject } & \multicolumn{2}{|c|}{ Treatment } & \multicolumn{2}{|c|}{ Period } & \multicolumn{2}{|c|}{ Preparation } \\
\hline & $\mathrm{F}^{\mathrm{a}}$ & $P^{b}$ & $\bar{F}$ & $P$ & $F$ & $P$ & $F$ & $\mathbf{P}$ \\
\hline $\mathrm{LnC}_{\max }$ & 2.91 & 0.0077 & 3.90 & 0.0610 & 0.84 & 0.3686 & 1.64 & 0.2132 \\
\hline $\mathrm{LnAUC}_{0-\mathrm{t}}$ & 18.55 & 0.0000 & 1.35 & 0.2578 & 11.21 & 0.0029 & 16.52 & 0.0005 \\
\hline $\operatorname{LnAUC}_{0-\infty}$ & 22.19 & 0.0000 & 0.58 & 0.4540 & 9.95 & 0.0046 & 21.16 & 0.0001 \\
\hline
\end{tabular}

${ }^{\mathrm{a}} \mathrm{F}=$ Fisher value

${ }^{\mathrm{b}} \mathrm{P}=$ probability value

The method is verified fully by selectivity, accuracy, precision, calibration curve and stability. The drug concentration was linear within the range of $0.05 \sim 10.0 \mu \mathrm{g} \times$ $\mathrm{L}^{-1}$. The lower limit of quantification was $0.05 \mu \mathrm{g} \times \mathrm{L}^{-1}$, and the equation was $\mathrm{Y}=0.55667 \mathrm{X}-0.0030182\left(\mathrm{r}^{2}=\right.$ 0.9949 ). The intra- and interday maximum precision was 5.4 and $4.8 \%$, respectively. The intra- and interday accuracy was $-6.7 \sim 3.9 \%$ and $-3.3 \sim 3.3 \%$, respectively. The extraction recovery of levamlodipine was $94.7 \pm 3.9 \%$. There was no significant interference in selectivity and stability.

\section{Pharmacokinetic analysis}

All subjects completed the study and the data were included in the pharmacokinetic analysis. The pharmacokinetic parameters were calculated according to noncompartment model with Phoenix ${ }^{\mathrm{mm}}$ WinNonlin 8.0 software (Pharsight, St. Louis, MO, USA). The value below the lower limit of quantification that occur before the first measurable concentration were set as zero. Subsequent values below the lower limit of quantification were excluded. The primary PK parameters were the maximum plasma concentration $\left(\mathrm{C}_{\max }\right)$, the area under the plasma concentration-time curve from 0 to the last measured time point $\left(\mathrm{AUC}_{0-\mathrm{t}}\right)$, and the area under the plasma concentration-time curve from 0 to infinity $\left(\mathrm{AUC}_{0-\infty}\right)$. The secondary PK parameters were the observed time to $\mathrm{C}_{\max }\left(\mathrm{T}_{\max }\right)$ and the apparent terminal half-life $\left(\mathrm{T}_{1 / 2}\right)$.

\section{Statistical analysis}

Analysis of variance (ANOVA) was performed on the logarithmically transformed $\mathrm{C}_{\max }, \mathrm{AUC}_{0-\mathrm{t}}$, and $\mathrm{AUC}_{0-\infty}$

Table 5 ANOVA results of main pharmacokinetic parameters in the fed group

\begin{tabular}{|c|c|c|c|c|c|c|c|c|}
\hline \multirow{2}{*}{$\begin{array}{l}\text { Dependent } \\
\text { variable }\end{array}$} & \multicolumn{2}{|c|}{ Subject } & \multicolumn{2}{|c|}{ Treatment } & \multicolumn{2}{|c|}{ Period } & \multicolumn{2}{|c|}{ Preparation } \\
\hline & $\overline{F^{a}}$ & $P^{b}$ & $F$ & $P$ & $F$ & $P$ & $\bar{F}$ & $P$ \\
\hline $\mathrm{LnC}_{\max }$ & 6.49 & 0.0000 & 0.01 & 0.9110 & 1.22 & 0.2819 & 1.08 & 0.3101 \\
\hline $\operatorname{LnAUC}_{0-\mathrm{t}}$ & 13.50 & 0.0000 & 0.11 & 0.7425 & 4.91 & 0.0373 & 0.01 & 0.9302 \\
\hline $\operatorname{LnAUC}_{0-\infty}$ & 15.68 & 0.0000 & 0.04 & 0.8485 & 3.51 & 0.0745 & 0.01 & 0.9404 \\
\hline
\end{tabular}

to assess the effects from subject, treatment, period, and preparation. Statistical data were presented as mean \pm standard deviation (SD). The probability value less than 0.05 is considered statistically significant. The GMRs of the primary PK parameters and their $90 \%$ confidence intervals (CIs) were calculated. If it is within the equivalent range $(80 \sim 125 \%)$, it is judged as bioequivalence, and the results of double unilateral t-test are listed. $T_{\max }$ was analyzed by non-parametric statistical test. Statistical analyses were performed by SAS 9.4 (SAS Institute Inc. Cary, NC, USA).

\section{Results}

\section{Characteristics of the subjects}

All subjects completed the study. A total of 24 subjects including 6 women and 18 men enrolled in the fasted group. Among them, 23 were Han and 1 was Manchu nationality. Parameter, mean \pm SD (range): age, $31.04 \pm$ 8.04 years $(19.00 \sim 48.00$ years $)$; weight, $62.06 \pm 8.59 \mathrm{~kg}$ $(48.00 \sim 83.00 \mathrm{~kg}) ; \quad$ height, $168.27 \pm 7.97 \mathrm{~cm} \quad(152.00 \sim$ $185.00 \mathrm{~cm}$ ); body mass index (BMI), $21.90 \pm 2.57 \mathrm{~kg} \times$ $\mathrm{m}^{-2}\left(19.00 \sim 27.90 \mathrm{~kg} \times \mathrm{m}^{-2}\right)$. A total of 24 subjects including 6 women and 18 men enrolled in the fed group. All of them were Han nationality. Parameter, mean \pm SD (range): age, $32.46 \pm 10.45$ years $(18.00 \sim 51.00$ years); weight, $66.88 \pm 8.8 \mathrm{~kg}(50.00 \sim 81.00 \mathrm{~kg})$; height, $167.77 \pm$ $6.63 \mathrm{~cm} \quad(154.00 \sim 178.00 \mathrm{~cm}) ; \quad$ BMI, $23.76 \pm 2.86 \mathrm{~kg} \times$ $\mathrm{m}^{-2}\left(18.90 \sim 28.30 \mathrm{~kg} \times \mathrm{m}^{-2}\right)$.

\section{Pharmacokinetics}

Following a single dose of test formulations or reference formulations, the mean plasma concentration-time curves were shown in Fig. 2 (the fasted group) and Fig. 3 (the fed group). Individual plasma concentration-time data of levamlodipine was show supplementary file.

Table 6 90\% Cls for the geometric mean ratios of $C_{\text {max }}, A \cup C_{0-t}$, and $\mathrm{AUC}_{0-\infty}$ in the fasted group $(n=24)$

\begin{tabular}{llll}
\hline Parameter & T/R (\%) & $\mathbf{9 0 \% ~ C l s}$ & Power (\%) \\
\hline$C_{\max }$ & 95.41 & $89.59-101.61 \%$ & 99.87 \\
AUC $_{0-\mathrm{t}}$ & 91.28 & $87.83-94.87 \%$ & 100.00 \\
AUC $_{0-\infty}$ & 89.81 & $86.28-93.49 \%$ & 99.92 \\
\hline
\end{tabular}


Table $790 \%$ Cls for the geometric mean ratios of $C_{\text {max }}, A \cup C_{0-t}$, and $\mathrm{AUC}_{0-\infty}$ in the fed group $(n=24)$

\begin{tabular}{llll}
\hline Parameter & T/R (\%) & 90\% Cls & Power (\%) \\
\hline$C_{\max }$ & 96.48 & $90.93-102.37 \%$ & 99.98 \\
AUC $_{0-\mathrm{t}}$ & 100.24 & $95.75-104.93 \%$ & 100.00 \\
AUC $_{0-\infty}$ & 100.22 & $95.36-105.33 \%$ & 100.00 \\
\hline
\end{tabular}

Mean pharmacokinetic parameters from the fasted group (Table 2) and the fed group (Table 3) are summarized. In the fasted group (Table 4), ANOVA for $\mathrm{C}_{\text {max }}$, $\mathrm{AUC}_{0-\mathrm{t}}$, and $\mathrm{AUC}_{0-\infty}$ indicated a lack of effects on treatment. ANOVA for $C_{\max }$ indicated a significant difference in subjects $(p \leq 0.05)$. ANOVA for $\mathrm{AUC}_{0-\mathrm{t}}(p \leq$ $0.05)$ and $\mathrm{AUC}_{0-\infty}(p \leq 0.05)$ indicated a significant difference in formulations and preparations. In the fed group (Table 5), ANOVA for $\mathrm{C}_{\max }, \mathrm{AUC}_{0-\mathrm{t}}$, and $\mathrm{AUC}_{0-\infty}$ indicated a lack of effects in treatments and preparations. ANOVA for $\mathrm{C}_{\max }(p \leq 0.05), \mathrm{AUC}_{0-\mathrm{t}}(p \leq 0.05)$, and $\mathrm{AUC}_{0-\infty}(p \leq 0.05)$ indicated a significant difference in subjects. ANOVA for $\mathrm{AUC}_{0-\mathrm{t}}$ indicated a significant difference in periods $(p \leq 0.05)$.

The $90 \%$ CIs for the GMRs of $C_{\max }, \mathrm{AUC}_{0-\mathrm{t}}, \mathrm{AUC}_{0-\infty}$ and the power were presented in Table 6 (the fasted group) and Table 7 (the fed group). These ratios were within the predefined equivalence limit of $80 \sim 125 \%$.

\section{Safety}

During the whole study period, both test preparation and reference preparation showed good tolerance. The AEs found in physical examination, 12-lead ECG and laboratory examination were listed in Table 8 (the fasted group) and Table 9 (the fed group). None of them were judged as serious adverse events (SAEs).

\section{Discussion}

On March 5, 2016, the general office of the State Council of the people's Republic of China issued opinions on the quality and efficacy consistency evaluation of generic drugs. Accordingly, the present study was performed to compare the pharmacokinetics of a newly-developed levamlodipine besylate tablet at a single dose of $5 \mathrm{mg}$ (test formulation, anglikang Pharmaceutical Company Co., Ltd., Zhejiang, China) with that of a marketed amlodipine besylate tablet at a single dose of $10 \mathrm{mg}$ (reference formulation, Pfizer Pharmaceuticals Limited, USA) for assessment of bioequivalence in healthy Chinese volunteers under fasted and fed conditions. The two medicinal products are bioequivalent when their 90\% CI of the $\mathrm{AUC}_{0-\mathrm{t}}, \mathrm{AUC}_{0-\infty}$ and $\mathrm{C}_{\max }$ of the reference preparation over the test preparation fall between the predetermined limits of $80 \sim 125 \%$. The two medicinal formulations were well tolerated. No subject withdrew from the study due to any AEs, and no SAEs occurred.

Amlodipine besylate tablets were developed by Pfizer Pharmaceutical Co., Ltd., in which the ratio of (R)-amlodipine to (S)-amlodipine is 1:1. The active component of amlodipine is (S)-amlodipine, also known as levamlodipine. In vivo, there is no mutual transformation between (R)-amlodipine and (S)-amlodipine. Before this study (November 13, 2019), there is no approved levamlodipine besylate tablet in the European Union, the United States, Japan, and China. Moreover, the pharmaceutical research of the the new developed test formulation is carried out according to the amlodipine besylate tablets developed by Pfizer. Combined with Chinese drug consistency evaluation catalogue, amlodipine besylate tablets $\left(\right.$ Norvasc $\left.^{\odot}\right)$ produced by Pfizer was selected as the reference formulation in this study. On December 19, 2019, levamlodipine maleate tablets (Conjupri ${ }^{\oplus}$ ) produced by CSPC Ouyi pharmaceutical Co., Ltd. was

Table 8 Adverse events in the fasted group

\begin{tabular}{|c|c|c|c|}
\hline Random number & AEs & Treatment & Relationship with the formulations \\
\hline K002 & Cholesterol rise & $\mathrm{R}$ & Probably related \\
\hline K003 & Increased RBC count in urine & T & Probably related \\
\hline K004 & Urinary leukocyte positive & R & Probably related \\
\hline K006 & Toothache & $\mathrm{R}$ & Probably related \\
\hline K011 & Anemia & R & Probably related \\
\hline \multirow[t]{3}{*}{ K012 } & Leukocyte count increased & T & Probably related \\
\hline & Toothache & T & Probably related \\
\hline & Neutrophil count increased & T & Probably related \\
\hline K017 & Anemia & $\mathrm{R}$ & Probably related \\
\hline K021 & Triglyceride rise & $\mathrm{R}$ & Probably related \\
\hline K022 & Rhinorrhea & $\mathrm{R}$ & Probably related \\
\hline K023 & Trauma of right foot & $\mathrm{R}$ & Definitely not \\
\hline
\end{tabular}


Table 9 Adverse events in the fed group

\begin{tabular}{llll}
\hline Random number & AEs & Treatment & Relationship with the formulations \\
\hline F003 & Vasovagal response & T & May be irrelevant \\
& Toothache & $R$ & Probably related \\
F010 & New degree I atrioventricular block & $T$ & Probably related \\
F014 & Vasovagal response & $T$ & May be irrelevant \\
& Triglyceride rise & $\mathrm{R}$ & Probably related \\
F015 & Triglyceride rise & $\mathrm{T}$ & Probably related \\
F017 & Triglyceride rise & $\mathrm{T}$ & Probably related \\
F019 & Prolonged APTT & Probably related \\
\hline
\end{tabular}

${ }^{\mathrm{a}} A P T T$ activated partial thromboplastin time

approved by FDA. However, the acid radical of this product is different from the test formulation in this study. Therefore, NMPA approved that amlodipine besylate tablets developed by Pfizer was selected as the reference preparation in this study.

In this study, the parameters such as recoveries, matrix effects, linear range, lower limit of quantification, stability by specificity, precision, and accuracy specifications, were investigated to confirm the method of LC-MS/MS. Concentration of levamlodipine in human plasma showed good linear relationship within $0.05 \sim 10 \mu \mathrm{g} \times \mathrm{L}^{-1}$. The relative standard deviation (RSD) values of intra- and interday precision were both less than $10 \%$. The matrix effect induced by endogenous interfering substances in biological samples did not affect the ionization efficiency and signal intensity of levamlodipine [9]. According to FDA bioequivalence guidance, the final elimination half-life of amlodipine is about $30 \sim 50 \mathrm{~h}$. Thus, washout period is set to 21 days, which is a length of time greater than seven half lives. And the blood samples taken for $168 \mathrm{~h}$ was enough.

In view of the inhibitory effect of amlodipine on CYP3A4 [10], subjects with behaviors of drinking, smoking and drug intake through CYP3A4 metabolism were excluded. During the trial, the administration of drugs metabolized by CYP3A4 did not occur. As an open-label study, AEs assessment may not be objective enough. When the test formulation passes the evaluation and enters the market, the efficacy and side effects need to be further explored.

\section{Conclusions}

The trial confirmed that levamlodipine at a single dose of $5 \mathrm{mg}$ and amlodipine at a single dose of $10 \mathrm{mg}$ were bioequivalent under both fasted condition and fed condition. If the test formulation levamlodipine can be approved by NMPA, it can be used in the treatment of hypertension in clinic.

\section{Supplementary Information}

The online version contains supplementary material available at https://doi. org/10.1186/s40360-020-00459-6.

\section{Additional file 1.}

\section{Abbreviations}

LC-MS/MS: Liquid chromatography-tandem mass spectrometry;

Cls: Confidence intervals; GMRs: Ratio of geometric means; GCP: Good clinical practice; NMPA: China National Medical Products Administration; HIV: Human immunodeficiency virus; AEs: Adverse events; SPE: Solid-phase extraction; AUC: Area under curve; $C_{\text {max }}$ : Maximum plasma concentration; $T_{\text {max }}$ : Time to $\mathrm{C}_{\text {max }} T_{1 / 2}$ : Elimination half-life; SD: Standard deviation; BMI: Body mass index; ECG: Electrocardiogram; SAEs: Serious adverse events; RSD: Relative standard deviation

\section{Acknowledgments}

We are grateful to anglikang Pharmaceutical Company Co., Ltd. Suzhou and Shenglin Pharmaceutical Technology Co., Ltd.

\section{CONSORT guidelines}

The study adheres to CONSORT guidelines and include a completed CONSORT checklist as an additional file.

\section{Authors' contributions}

The study was designed by YC. XL wrote the paper, participated in data statistics and performance. CJW, T L, YPL, SQL, YT, YPM and XMG performed research. The author(s) read and approved the final manuscript.

\section{Funding}

Test execution and data collection in this work were supported by grants from the National Major Scientific and Technological Special Project for "Significant New Drugs Development" (2020ZX09201-018). Layout fee of publication was supported by the China Postdoctoral Science Foundation (2016 M602100)

\section{Availability of data and materials}

We have shared the raw data by providing it in a supplementary file.

\section{Ethics approval and consent to participate}

The study passed the review of Medical Ethics Committee of the Affiliated Hospital of Qingdao University on August 30, 2018, and obtained the approval (No.: QYFYEC 2018-065-01). The written informed consents was obtained from all participants.

Consent for publication

Not applicable

Competing interests

The authors report no conflicts of interest. 
Received: 31 July 2020 Accepted: 10 November 2020

Published online: 19 November 2020

\section{References}

1. Katholi RE, Couri DM. Left ventricular hypertrophy: major risk factor in patients with hypertension: update and practical clinical applications. Int J Hypertens. 2011;2011:495349.

2. Johnson R, Dludla P, Mabhida S, et al. Pharmacogenomics of amlodipine and hydrochlorothiazide therapy and the quest for improved control of hypertension: a mini review. Heart Fail Rev. 2019;24(3):343-57.

3. Liu F, Qiu M, Zhai SD. Tolerability and effectiveness of (S)-amlodipine compared with racemic amlodipine in hypertension: a systematic review and meta-analysis. Curr Ther Res Clin Exp. 2010;71(1):1-29.

4. Striessnig J, Ortner NJ, Pinggera A. Pharmacology of L-type calcium channels: novel drugs for old targets? Curr Mol Pharmacol. 2015:8(2):110-22

5. Lu Y, Yin J, Wu X, Fan Y, Liu F. Comparative effects of $2.5 \mathrm{mg}$ levamlodipine and $5 \mathrm{mg}$ amlodipine on vascular endothelial function and atherosclerosis. Pak J Pharm Sci. 2019;32(5(Special)):2433-6.

6. Xu SM, Wang YL, Li D, et al. Randomized, two-way crossover bioequivalence study of levamlodipine besylate tablets in healthy Chinese subjects. Int J Clin Pharmacol Ther. 2017;55(10):818-24.

7. World Medical A. World medical association declaration of Helsinki: ethical principles for medical research involving human subjects. JAMA. 2013; 310(20):2191-4.

8. Takezawa M. Good clinical practice (GCP) in clinical trials. Nihon Yakurigaku Zasshi. 2011:138(5):205-8.

9. Shentu J, Fu L, Zhou H, et al. Determination of amlodipine in human plasma using automated online solid-phase extraction HPLC-tandem mass spectrometry: application to a bioequivalence study of Chinese volunteers. J Pharm Biomed Anal. 2012;70:614-8.

10. Zhu Y, Wang F, Li Q, et al. Amlodipine metabolism in human liver microsomes and roles of CYP3A4/5 in the dihydropyridine dehydrogenation. Drug Metab Dispos. 2014;42(2):245-9.

\section{Publisher's Note}

Springer Nature remains neutral with regard to jurisdictional claims in published maps and institutional affiliations.

Ready to submit your research? Choose BMC and benefit from:

- fast, convenient online submission

- thorough peer review by experienced researchers in your field

- rapid publication on acceptance

- support for research data, including large and complex data types

- gold Open Access which fosters wider collaboration and increased citations

- maximum visibility for your research: over $100 \mathrm{M}$ website views per year

At BMC, research is always in progress.

Learn more biomedcentral.com/submissions 